\title{
Modelling and numerical simulations of larval migration of the sole (Solea solea (L.)) of the Bay of Biscay. Part 2: numerical simulations
}

\author{
Azeddine RAMZI ${ }^{a}$, Ovide ARINO ${ }^{\mathrm{b} *}$, Constantine KOUTSIKOPOULOS ${ }^{\mathrm{c}}$, Ahmed BOUSSOUAR ${ }^{\mathrm{b}}$, \\ Pascal LAZURE ${ }^{d}$ \\ a INRH, 2, rue Tiznit, Casablanca, Morocco \\ ${ }^{\mathrm{b}}$ UR Geodes, IRD centre de Bondy, 32, avenue Henri-Varagnat, 93143 Bondy, France \\ ${ }^{c}$ Department of Biology, University of Patras, 26500 Patras, Greece \\ d Ifremer-Brest, B.P.70, 29280 Plouzané, France
}

Received 14 September 2000; accepted 15 October 2000

\begin{abstract}
This paper is the second part of a work on the modelling of larval migration and growth for the sole of the Bay of Biscay (Solea solea (L.)). The goal of the paper is twofold: first of all, it aims at presenting a numerical application of the formulae (concerning the recruitment rate) elaborated in the first paper. Results show a high sensitivity with respect to some parameters. Then, a comparison is made with a numerical model using a 3D circulation model provided by Ifremer. (C) 2001 Ifremer/CNRS/IRD/Éditions scientifiques et médicales Elsevier SAS
\end{abstract}

Résumé - Modélisation et simulations de la migration des larves de sole, Solea solea (L.), du golfe de Gascogne, $2^{\mathbf{e}}$ partie : simulation. Cet article est la deuxième partie d'un travail sur la modélisation des processus de migration et croissance larvaire de la sole du golfe de Gascogne (Solea solea (L.)). L'article a un double objectif : d'abord, présenter une application numérique des formules (sur le taux de recrutement) établies dans le premier article ; les résultats montrent une grande sensibilité par rapport à certains des paramètres du modèle, ensuite, de comparer ce modèle avec un modèle numérique de déplacement utilisant un modèle de circulation $3 \mathrm{D}$ mis au point à l'Ifremer. (C) 2001 Ifremer/CNRS/IRD/Éditions scientifiques et médicales Elsevier SAS

population dynamics / diffusion and advection processes / recruitment

dynamique de population / processus de diffusion et d'avection / recrutement

\section{INTRODUCTION}

In the first part of this study (Ramzi et al., 2001), a 2D mathematical model describing the dynamics of the larva of the Dover sole, Solea solea (L.), of the Bay of Biscay has been derived. The model is itself an extension of a 1D model presented in (Arino et al., 1996). Our goal here is two-fold: first of all, using the formulae stated in part 1 of

* Correspondence and reprints.

E-mail address: ovide.arino@bondy.ird.fr (O. ARINO). this study (Ramzi et al., 2001), and data extracted from the literature, we perform a computational analysis of the recruitment. The main formula is a lower estimate of the rate of recruitment, which reads as:

$R_{\text {low }}(s)=\int_{D} S_{L}\left(a^{*}(s)\right) \inf _{Y \in \Omega} k_{L}\left(a^{*}(s), X, Y ; u\right) d X$

The formula relates the recruitment to various factors, including some characteristic features of the spawning ground and the nursery. A prerequisite for the computation of (1) is the determination of the age at the beginning 
of metamorphosis. For this, it is necessary to have available specific functions, which give the duration of a stage at a given temperature, to be used as shown in part 1 of this study (Ramzi et al., 2001). We use functions described in detail in (Horwood, 1993). Compared to recent findings reported in (Amara and Lagardère, 1995), the values we compute in paragraph 2.3 for the time spent from egg fertilization to the beginning of metamorphosis tend to be an overestimate, while the mean length of the sole at this stage is about the same, $8.5 \mathrm{~mm}$. Computations have been made in a number of cases, showing in fact a wide range of sensitivity of the parameters: the current speed in particular has a dramatic effect, since it appears that changing this parameter by an order of magnitude may entail changes in the recruitment rate of several orders.

As a secondary goal, section three presents numerical simulations of larval dispersion based on a completely different approach from the one followed in part 1 of this study (Ramzi et al., 2001). In this section, we are using a model for the migration and growth of the larvae that is very close, after obvious modifications, to a model for the dynamics of the larvae of the Bay of Biscay anchovy. Such a model was built up and investigated in the framework of a European project, and is amply discussed in (Arino and Prouzet, 1998; Arino et al., 1999). To summarize its main features, the model describes growth as a function of the temperature and migration as the result of 3D advection by currents and 1D (vertical) diffusion. Current introduces itself as a forcing term, computed by means of a simulation model due to Lazure and Jegou (1998). In the absence of data on the initial egg distribution for the sole, simulations were run starting from a guessed initial egg patch seeded in the spawning ground.

The organization of the paper is as follows: section two deals with numerical computations using formula (1). A central ingredient of the formula is the age at metamorphosis $a^{*}(t)$, as a function of the birth date, evaluated as the sum of the durations of the stages preceding the metamorphosis. The computation of the various stages is carried out in some detail in the next three paragraphs. Section three is devoted to simulations by means of the above-mentioned 3D model. The main new feature, compared to the model used in section two, is vertical migration, both the passive migration induced by currents and the active one corresponding to circadian movement. Finally, the two approaches are compared in a short discussion.

\section{ESTIMATE OF THE PROPORTION OF FERTILIZED EGGS REACHING METAMORPHOSIS}

The first step in establishing an estimate of the proportion of fertilized eggs reaching metamorphosis is to determine the function $a_{*}(t)$, the duration of the development of the larva from egg fertilization to the beginning of metamorphosis. Following the literature, we can subdivide this period into a number of stages, from fertilization to hatching (I, II, III, IV) and a number of stages in the larval phase (stages 1 through 4, the first one being the yolksac stage (Koutsikopoulos et al., 1991; Horwood, 1993). It is convenient for the ease of further computations to group stages 2, 3 and 4 as a single stage, simply called 'active', starting at the end of the yolksac period and ending at the beginning of metamorphosis.

\subsection{Duration of the stages from spawning to hatching}

According to (Horwood, 1993) we have the following expressions for the duration of each of the stages preceding hatching. The notation $D_{J}$ stands for the duration of stage $J$.

$$
\begin{array}{ll}
\text { stage } I & \ln \left(D_{I}\right)=2.0193-0.1227 T \\
\text { stage } I I & \ln \left(D_{I I}\right)=1.4941-0.1530 T \\
\text { stage } I I I & \ln \left(D_{I I I}\right)=2.5075-0.1509 T \\
\text { stage } I V & \ln \left(D_{I V}\right)=1.4106-0.0687 T
\end{array}
$$

This yields:

$$
\begin{aligned}
D_{I} & =7.533 \exp -0.1227 T \\
D_{I I} & =4.4553 \exp -0.1530 T \\
D_{I I I} & =12.274 \exp -0.509 T \\
D_{I V} & =4.0984 \exp -0.0687 T
\end{aligned}
$$

As an example, at $T=10^{\circ} \mathrm{C}$, we find the following values:

$$
D_{t}=2.1865 ; D_{I I}=0.9467 ; D_{I I I}=2.7142 ; D_{I V}=2.0618
$$

So, the time from spawning to hatching at $T=10^{\circ} \mathrm{C}$ is equal to $D_{H}=7.9272$ days. 
Another formula for the time to hatching (Horwood, $1993)$ is $D_{H}=137.8 T^{-1.329}$ which, at $T=10^{\circ} \mathrm{C}$ gives $D_{H}=6.4602$ days.

As a brief comment, formulae like (2) which detail the duration of intermediate stages present the advantage of accounting for possible variations of temperature from the beginning to the end of the egg stage.

\subsection{Duration of the yolksac period}

A formula for the time to first feeding (end of the yolksac period) is given in (Horwood, 1993), that is, $D_{Y S}=270.9 T^{-1.383}$ which, at $T=10^{\circ} \mathrm{C}$, yields:

$$
D_{Y S}=11.215 \text { days }
$$

In fact, following the idea presented at the end of the previous paragraph, it is rather risky to use a single formula to describe such a long duration. We will not do this here: instead, we assume the time from hatching to the end of the yolksac period to be constant, equal to:

$$
D_{H, Y S}=4.5 \text { days }
$$

where $D_{H, Y S}=D_{Y S}-D_{H}$. In order to determine the time to metamorphosis, we introduce the length at age, starting at the beginning of active feeding:

$$
w=w_{0} \exp (\beta(T) d)
$$

In this formula, $d$ is the time elapsed from the beginning of the active feeding, and $w_{0}$ is the initial length. Assuming that metamorphosis starts at a length $w^{*}$, the duration of the active feeding stage, from the end of the yolksac period through the beginning of the metamorphosis, is:

$$
D_{a c t}=(\beta(T))^{-1} \ln \left(\frac{w^{*}}{w_{0}}\right)
$$

where (Horwood, 1993, p.256)

$$
\beta(T)=-0.056+0.0092 T-0.00019 T^{2}
$$

The function $\beta(T)$ is increasing for $T$ in the interval (Arino and Prouzet, 1998), which is the range of allowable values of the temperature in the Bay of Biscay. The subscript act stands for active feeding. If we assume $w_{0}=4 \mathrm{~mm} ; w^{*}=10 \mathrm{~mm}$ we have, for $T=10^{\circ} \mathrm{C}$ :

$$
D_{a c t}=53.899 \text { days }
$$

If we assume that the length at the beginning of metamorphosis and $T=10^{\circ} \mathrm{C}$ is $8.5 \mathrm{~mm}$, we obtain: $D_{a c t}=44.34$ days, so that the total duration from spawning to the beginning of metamorphosis, that is to say: $D_{Y S}+D_{a c t}$, lies between 55.55 days and 66.32 days.

\subsection{Computation of the age at the beginning of metamorphosis as a function of the birth date}

We now give a formula for the age to begin metamorphosis $a_{*}(t)$ as a function of the date of birth $t$ in terms of the ages to stage $I, I I, I I I$ and $I V$ and the duration of the active feeding stage. For each time $t$, we denote $a_{*}^{J}(t)$ the duration of the $J^{\text {th }}$ stage, where $J=I, I I$, III, or $I V$, act in terms of the time when this stage begins, and we use the following notations: $t_{I}=t_{I}(t)$ is the time at the end of the first stage, $t_{I I}=t_{I I}(t)$ is the time at the end of the second stage, etc. We have the following obvious relationships:

$$
\begin{aligned}
t_{I}(t) & =t+a_{*}^{I}(t) \\
t_{I I}(t) & =t_{I}(t)+a_{*}^{I I}\left(t_{I}(t)\right) \\
t_{I I I}(t) & =t_{I I}(t)+a_{*}^{I I I}\left(t_{I I}(t)\right) \\
t_{I V}(t) & =t_{I I I}(t)+a_{*}^{I V}\left(t_{I I I}(t)\right) \\
t_{\text {act }}(t) & =t_{I V}(t)+4.5+a_{*}^{a c t}\left(t_{I V}(t)+4.5\right)
\end{aligned}
$$

where we have used the estimate of 4.5 days for the duration of the yolksac stage. From formula (5), we obtain immediately:

$$
a_{*}(t)=t_{a c t}(t)-t
$$

The calculation of each $a_{J}^{*}(t)$ is done the same way as in part 1 of this study, paragraph 4.2.1 (Ramzi et al., 2001), that is, $a_{*}^{J}(t)$ is obtained as the root of the following equation:

$$
\int_{t}^{t+a} \frac{1}{D_{J}(T(s))} d s=1
$$

Suppose for example that

$$
T(t)=T_{0}+T_{m} \sin (\alpha t+\gamma)
$$

$T_{0}$ would be a mean temperature, say $T=10^{\circ} \mathrm{C}$ while the other term would correspond to oscillations near $T_{0}$, $T_{m}=2^{\circ} \mathrm{C}$ and

$$
\alpha=\frac{2 \pi}{7} \quad \text { and } \quad \gamma=0
$$


The time unit is day. We assume that $t=0$ is the birth date of a cohort of larvae. So, the first computation to be made is the one of $a_{*}^{I}(t)$ and, for this, we have to solve for $a$ such that:

$$
\int_{0}^{a} \frac{1}{D_{I}(T(s))} d s=1
$$

that is, using 2 ,

$$
\int_{0}^{a}(7.533)^{-1} \exp \left(0.1227\left(10+2 \sin \left(\frac{2 \pi}{7} s\right)\right)\right) d s=1
$$

A reasonable approximation of $a_{*}^{I}$ is 1.86 days. We then turn to the computation of $a_{*}^{I I}(t)$, using the formula:

$$
\int_{0}^{a} \frac{1}{D_{I I}(T(s+1.86))} d s=1
$$

or,

$$
\int_{0}^{a} \frac{1}{4.4553 \exp \left(-0.1530\left(10+2 \sin \left(\frac{2 \pi}{7}(s+1.86)\right)\right)\right)} d s=1
$$

We obtain $a_{*}^{I I}(t)=0.73$ days, and $t_{I I}=2.59$ days. We now compute $a_{*}^{I I I}$. In analogy with the previous computations, we will obtain $a_{*}^{I I I}$ as a solution of:

$$
\int_{0}^{a} \frac{1}{12.274 \exp \left(-0.1509\left(10+2 \sin \left(\frac{2 \pi}{7}(s+2.59)\right)\right)\right)} d s=1
$$

We obtain $a_{*}^{I I I}(t)=2.95$ days, and $t_{I I I}=5.54$ days. We compute $a_{*}^{I V}$ as follows:

$$
\int_{0}^{a} \frac{1}{4.0984 \exp \left(-0.0687\left(10+2 \sin \left(\frac{2 \pi}{7}(s+5.54)\right)\right)\right)} d s=1
$$

We obtain $a_{*}^{I V}(t)=2.14$ days, and $t_{I V}=7.68$ days. We add 4.5 days for the yolksac period, so that the end of the yolksac period, which is also the beginning of the active feeding period is $t_{y s}=12.18$ days. The duration of that period is the solution of the following equation:

$$
\int_{0}^{a} \frac{1}{D_{a c t}(T(s+12.18))} d s=1
$$

which, in terms of the expressions stated above, reads:

$$
\begin{gathered}
\left(\ln \left(\frac{w^{*}}{w_{0}}\right)\right)^{-1} \int_{0}^{a} \beta(T(s+12.18)) d s=1 \\
\text { or, } \\
\left(\ln \left(\frac{w^{*}}{w_{0}}\right)\right)^{-1} \int_{0}^{a}[-0.056+0.0092 \\
\left(10+2 \sin \left(\frac{2 \pi}{7}(s+12.18)\right)\right) \\
\left.-0.00019\left(10+2 \sin \left(\frac{2 \pi}{7}(s+12.18)\right)\right)^{2}\right] d s=1
\end{gathered}
$$

With $w_{0}=4 \mathrm{~mm}$ and $w^{*}=8.5 \mathrm{~mm}$, we obtain $a_{*}^{a c t}(t)=45.465$ days, so that $t_{a c t}=57.645$ days which, in this case, is also the time to juvenile stage, that is, $a=57.645$ days.

\subsection{A lower estimate of the rate of larvae initiating metamorphosis}

We are going to compute a lower estimate of the rate of metamorphosis using formula (1). We note that the formula is the product of two independent quantities: $S_{L}\left(a_{*}(s)\right)$, the survival rate up to the beginning of metamorphosis, and:

$$
\rho_{D, \Omega}(s)={ }_{d e f} \int_{D} \inf _{Y \in \Omega} k_{L}\left(a_{*}(s), X, Y ; u\right) d X
$$

a lower estimate of the rate of migration from $\Omega$ at age 0 to $D$ at age $a_{*}(s) ; s$ being the birth date. That the two processes, the demographic one and the physical one, are independent follows from the assumption that the movement is supposed to be entirely governed by physical environment. Since our main interest here is in determining the specific role of the physical environment and especially the role of diffusion on the recruitment, we will now concentrate on the computation of expression (6). For this, we need to estimate several parameters, those defining a spawning area $\Omega$ and a nursery area $D$, the diffusion matrix $K$ and the advective component $u$, and $a_{*}(s)$. According to the estimates given in paragraph 2.3 and the literature (Horwood, 1993; Koutsikopoulos et al., 1991), it is legitimate to assume that the range of the values of $a_{*}(s)$ is within the interval [40,60] days.

As concerns the geographic location, we consider part of the spawning ground and nurseries north-east of the Bay 
of Biscay, offshore from the Loire estuary (Koutsikopoulos et al., 1991). The spawning ground is roughly parallel to the coast, between isobaths $100 \mathrm{~m}$ and $50 \mathrm{~m}$, while the nursery is within the $20 \mathrm{~m}$ isobath. To this rough description, is associated a coordinate system made up of a line perpendicular to the coast with inshore-offshore positive orientation, as a first axis $\left(x_{1}\right)$ and a line SE-NW, which is located inside the $20-40 \mathrm{~m}$ isobath, as the second axis $\left(x_{2}\right)$, and the zero of the second coordinate, that is, on the axis 'parallel' to the coast, corresponds to the estuary of the Loire river. We assume that:

$$
\Omega=\left[\omega_{1}^{1}, \omega_{2}^{1}\right] \times\left[\omega_{1}^{2}, \omega_{2}^{2}\right] \text { and } D=\left[d_{1}^{1}, d_{2}^{1}\right] \times\left[d_{1}^{2}, d_{2}^{2}\right]
$$

where $\omega_{1}^{i}<\omega_{2}^{i}$ and $d_{1}^{i}<d_{2}^{i}$ for $i=1,2$. We will also assume that $d_{2}^{1}<\omega_{1}^{1}$, that is, there is no overlap between the nursery and the spawning areas. Finally, to facilitate some of the calculations to come, we also assume that $d_{1}^{1}>0$ and $d_{1}^{2}<\omega_{1}^{2}<\omega_{2}^{2}<d_{2}^{2}$. The latter assumption is in fact quite natural. It means that we expect that the larvae will diffuse both northward and southward from the spawning area. As an example, we might consider:

$$
\Omega=[80 \mathrm{~km} ; 120 \mathrm{~km}] \times[20 \mathrm{~km} ; 20 \mathrm{~km}]
$$

and,

$$
D=[20 \mathrm{~km} ; 40 \mathrm{~km}] \times[-40 \mathrm{~km} ; 40 \mathrm{~km}]
$$

The mean drift speed is about $1-30 \mathrm{~cm} \mathrm{~s}^{-1}$ and is parallel to the $x_{2}$ axis and oriented northwestward (Koutsikopoulos et al., 1991), so that $u$ is of the form $u=\left(0, u_{2}\right)$ with $u_{2} \geq 0$.

Values for $K$ were found in the literature (Pond and Pickard, 1983), we assume $K$ to be diagonal and $k_{1,1}=$ $k_{2,2}=k=10^{2}-10^{4} \mathrm{~cm}^{2} \mathrm{~s}^{-1}$.

Using some of the formulae derived in part 1 of this study (Ramzi et al., 2001, section three) and notations introduced therein, we arrive at the following inequality:

$$
\begin{gathered}
\int_{D} \inf _{Y \in \Omega} k_{L}^{1}(a, X, Y ; u) d X \geq \\
\frac{1}{4 \pi a k} \exp \left(-\frac{\left(u_{2}\right)^{2} a}{4 k}\right) \int_{d_{1}^{1}}^{d_{2}^{1}} \exp \left(-\frac{\left(x_{1}-\omega_{2}^{1}\right)^{2}}{4 k a}\right) d x_{1} \\
\times\left(\int_{d_{1}^{2}}^{\frac{\omega_{1}^{2}+\omega_{2}^{2}}{2}} \exp \left(-\frac{u_{2}\left(x_{2}-\omega_{2}^{2}\right)}{k}-\frac{\left(\omega_{2}^{2}-x_{2}\right)^{2}}{4 k a}\right) d x_{2}\right. \\
\left.+\int_{\frac{\omega_{1}^{2}+\omega_{2}^{2}}{2}}^{d_{2}^{2}} \exp \left(\frac{u_{2}\left(x_{2}-\omega_{2}^{2}\right)}{k}-\frac{\left(\omega_{1}^{2}-x_{2}\right)^{2}}{4 k a}\right) d x_{2}\right)
\end{gathered}
$$

The only change in the estimate for $k_{L}^{2}$ is that $\left(x_{1}-\omega_{2}^{1}\right)$ becomes $\left(x_{1}+\omega_{2}^{1}\right)$ in the integral on the right of (7). We are now in position to propose an estimate for $\int_{D} \inf k_{L}\left(a^{*}(s), X, Y ; u\right) d X$ that is,

$$
\begin{gathered}
\rho_{D, \Omega}(s) \geq \frac{1}{4 \pi a_{*}(s) k} \exp \left(-\frac{\left(u_{2}\right)^{2} a_{*}(s)}{4 k}\right) \\
\times\left(\int_{d_{1}^{1}}^{d_{1}^{1}}\left[\exp \left(-\frac{\left(x_{1}-\omega_{2}^{1}\right)^{2}}{4 k a_{*}(s)}\right)+\exp \left(-\frac{\left(x_{1}+\omega_{2}^{1}\right)^{2}}{4 k a_{*}(s)}\right)\right] d x_{1}\right) \\
\times\left(\int_{d_{1}^{2}}^{\omega_{1}^{2}+\omega_{2}^{2}} \exp \frac{u_{2}\left(x_{2}-\omega_{2}^{2}\right)}{k}-\frac{\left(\omega_{2}^{2}-x_{2}\right)^{2}}{4 k a_{*}(s)} d x_{2}\right. \\
\left.+\int_{\frac{\omega_{1}^{2}+\omega_{2}^{2}}{2}}^{d^{2}} \exp \frac{u_{2}\left(x_{2}-\omega_{2}^{2}\right)}{k}-\frac{\left(\omega_{1}^{2}-x_{2}\right)^{2}}{4 k a_{*}(s)} d x_{2}\right)
\end{gathered}
$$

The above estimate is expressed in terms of parameters and quantities all of which can be evaluated. As an example, we are now going to compute its value for the set of parameters we introduced above and a few other cases.

The units are as follows: the $\omega$ 's and the $d$ 's are in metres, the speed $u_{2}$ is in $\mathrm{m} \mathrm{s}^{-1}$ and the diffusion coefficient $k$ is in $\mathrm{m}^{2} \mathrm{~s}^{-1}$ : We assume in the next computations that $a_{*}(s)=55$ days $=4.755 .10^{6} \mathrm{~s}$. Each row of table $I$ is made up of a set of values for the parameters entering the computation of (8). A given set is denoted $E(i)$ where $E$ stands for 'experiment'. Table II gives the value of the right hand side of (8) associated with each experiment. We denote it $\widehat{E(i)}$. Each value is evaluated as a product of three quantities:

$$
\widehat{E(i)}=A \times B \times C
$$

where

$$
\left\{\begin{array}{l}
A=\frac{1}{4 \pi a_{*}(s) k} \exp \left(-\frac{\left(u_{2}\right)^{2} a_{*}(s)}{4 k}\right) \\
B=\int_{d_{1}^{1}}^{d_{2}^{1}}\left[\exp \left(-\frac{\left(x_{1}-\omega_{2}^{1}\right)^{2}}{4 k a_{*}(s)}\right)+\exp \left(-\frac{\left(x_{1}+\omega_{2}^{1}\right)^{2}}{4 k a_{*}(s)}\right)\right] d x_{1} \\
C=\int_{d_{1}^{2}}^{\omega_{1}^{2}+\omega_{2}^{2}} \exp \frac{u_{2}\left(x_{2}-\omega_{2}^{2}\right)}{k}-\frac{\left(\omega_{2}^{2}-x_{2}\right)^{2}}{4 k a_{*}(s)} d x_{2} \\
+\int_{\frac{\omega_{1}^{2}+\omega_{2}^{2}}{2}}^{d_{2}^{2}} \exp \frac{u_{2}\left(x_{2}-\omega_{2}^{2}\right)}{k}-\frac{\left(\omega_{1}^{2}-x_{2}\right)^{2}}{4 k a_{*}(s)} d x_{2}
\end{array}\right.
$$

Some comments are in order. Estimates inferior to $10^{-15}$ are of no interest since the number of eggs laid during a 
Table I. Ten different situations are proposed in this table.

\begin{tabular}{lcccccccccc}
\hline & $\omega_{1}^{1}$ & $\frac{\omega_{2}^{1}}{10^{3}}$ & $10^{3}$ & $\frac{\omega_{1}^{2}}{10^{3}}$ & $\frac{\omega_{2}^{2}}{10^{3}}$ & $\frac{d_{1}^{1}}{10^{3}}$ & $\frac{d_{2}^{1}}{10^{3}}$ & $\frac{d_{1}^{2}}{10^{3}}$ & $\frac{d_{2}^{2}}{10^{3}}$ & $u_{2}$ \\
\hline$E(1)$ & 80 & 120 & -20 & 20 & 20 & 40 & -40 & 40 & $10^{-1}$ \\
$E(2)$ & 80 & 120 & -20 & 20 & 20 & 40 & -40 & 40 & $10^{-2}$ \\
$E(3)$ & 80 & 90 & -20 & 20 & 20 & 40 & -40 & 40 & $10^{-1}$ \\
$E(4)$ & 80 & 90 & -2 & 2 & 20 & 40 & -40 & 40 & $10^{2}$ \\
$E(5)$ & 80 & 90 & -2 & 2 & 20 & 40 & -80 & 80 & $10^{-1}$ \\
$E(6)$ & 80 & 90 & -2 & 2 & 20 & 40 & -40 & 90 & $10^{-1}$ \\
$E(7)$ & 80 & 90 & -20 & 20 & 20 & 40 & -40 & 40 & $10^{-1}$ & $10^{2}$ \\
$E(8)$ & 80 & 90 & -20 & 20 & 20 & 40 & -40 & 40 & $10^{2}$ \\
$E(9)$ & 80 & 90 & -20 & 20 & 20 & 40 & -40 & 40 & $5 \times 10^{-1}$ \\
$E(10)^{*}$ & 80 & 90 & -20 & 20 & 20 & 40 & -40 & 40 & $5 \times 10^{2}$ \\
\hline
\end{tabular}

$E(10)$ is the same as $E(3)$ except for $a_{*}(s)=40$ days $=3.456 \times 10^{6} \mathrm{~s}$.

Table II. Intermediate $(A, B, C)$ values and estimated proportion $\widehat{E(i)}$ of larvae initiating metamorphosis for ten different situations $\widehat{E(i)}$ specified in table I.

\begin{tabular}{lllll}
\hline & $A$ & $B$ & $C$ & $E(i)$ \\
\hline$E(1)$ & $7.9052 \times 10^{-62}$ & $7.250 \times 10^{1}$ & $3.9228 \times 10^{10}$ & $2.2483 \times 10^{-49}$ \\
$E(2)$ & $1.0195 \times 10^{-8}$ & $3.2071 \times 10^{2}$ & $2.1077 \times 10^{4}$ & $6.8914 \times 10^{-2}$ \\
$E(3)$ & $7.9052 \times 10^{-62}$ & $3.1716 \times 10^{3}$ & $7.7923 \times 10^{10}$ & $1.9537 \times 10^{-47}$ \\
$E(4)$ & $7.9052 \times 10^{-62}$ & $3.1716 \times 10^{3}$ & $1.3168 \times 10^{19}$ & $3.3015 \times 10^{-39}$ \\
$E(5)$ & $7.9052 \times 10^{-62}$ & $3.1716 \times 10^{3}$ & $2.3892 \times 10^{35}$ & $5.9902 \times 10^{-23}$ \\
$E(6)$ & $7.9052 \times 10^{-62}$ & $3.1716 \times 10^{3}$ & $2.1326 \times 10^{39}$ & $5.3469 \times 10^{-19}$ \\
$E(7)$ & $2.3014 \times 10^{-16}$ & $2.5922 \times 10^{4}$ & $6.4438 \times 10^{4}$ & $3.8442 \times 10^{-7}$ \\
$E(8)$ & $3.1648 \times 10^{-21}$ & $1.8116 \times 10^{4}$ & $1.9829 \times 10^{5}$ & $1.1369 \times 10^{-11}$ \\
$E(9)$ & $4.1494 \times 10^{-23}$ & $3.1716 \times 10^{3}$ & $7.5541 \times 10^{6}$ & $9.9414 \times 10^{-13}$ \\
$E(10)^{*}$ & $1.381 \times 10^{-47}$ & $1.6291 \times 10^{3}$ & $3.9228 \times 10^{10}$ & $8.8255 \times 10^{-34}$ \\
\hline
\end{tabular}

whole spawning season is lower than $10^{14}$ (Horwood, 1993), so that in fact such an estimate is the same as a zero estimate. On the other hand, the estimate obtained using $E(2)$, which differs from the other simulations by the speed of the current, is very interesting: in this case, the rate of failure of the recruitment implied by physical causes is surprisingly low. Two other situations when the failure rate is reasonably low are $E(7)$ and $E(8)$. In these two cases, the diffusion coefficient was modified to a value higher than in the other cases, while the other parameters were left unchanged. Comparing the results of $E(8) / E(7)$ to those of $E(9) / E(2)$, one can see that the estimate is primarily sensitive to the current speed, the diffusion coefficient comes next in the scale of sensitivity; the geographic parameters $\omega_{j}^{i}$ and $d_{j}^{i}$ have a much lower impact. Finally, the age at metamorphosis does not influence the failure rate very much, as simulation $E(10)$ shows.

\section{INFLUENCE OF VERTICAL MIGRATION}

Figure 1 depicts variations of the horizontal components of the current as a function of depth, suggesting that the vertical position of a larva may have a significant influence on its horizontal movement, thus justifying the simulations undertaken in this section using a model where vertical migration is accounted for.

The model describes the movement of the larvae under the combined action of vertical diffusion and 3D- advection by currents. A quick description of the model is as follows: it is a purely mechanical model with no growth no death, focusing on the movement of sole. In addition, the model has a built-in mechanism that drives the circadian movement, with a strength which increases with age. We use a function of the following type:

$$
f(a, z)=\frac{\alpha(a, z) a}{12} \cos (2 \pi a), \text { for } a \geq 12
$$


which is to be added to the vertical component of the larva advection. Here, $a$ represents the age (in days) and it is assumed that the circadian movement starts after 12 days, that is, roughly after the yolksac resorption. In fact, it was considered that the direct effect of vertical diffusion on the movement of the larvae decays after the yolksac resorption, roughly after day 12 , and cancels out after day 22. The function $\alpha(a, z)$ takes effect in the upper part and the lower part of the column, being equal to zero when, and as long as the larva stays in the upper part and $\cos (2 \pi a)>0$ or stays in the lower part and $\cos (2 \pi a)<0$ respectively, and being equal to some positive constant $\bar{\alpha}$ otherwise. Multiplying by $a$ is a simple way to express the fact that the speed of the larva increases with age. It was also necessary to introduce some small upward vertical velocity given to the early eggs by the Archimedes law: this explains, rather than diffusion, that soon after spawning in the lower part of the water column the eggs are displaced upwards and tend to accumulate under the surface. An explanation for this would be that the relative density of eggs at this stage is lower than that of the water, which could be explained by the presence of "oil globules around the surface of the yolk" (Horwood, 1993). The upward effect on early eggs was modeled as follows:

$$
f(a, z)= \begin{cases}10^{-6} \mathrm{~m} \mathrm{~s}^{-1} & \text { for } a \leq 2.5 \text { days and } z \leq-40 \\ 2.10^{-6} \mathrm{~m} \mathrm{~s}^{-1} & \text { for } a \leq 2.5 \text { days and }-40<z \leq-30 \\ 3.10^{-6} \mathrm{~m} \mathrm{~s}^{-1} & \text { for } a \leq 2.5 \text { days and } z>-30\end{cases}
$$

$z=-10$

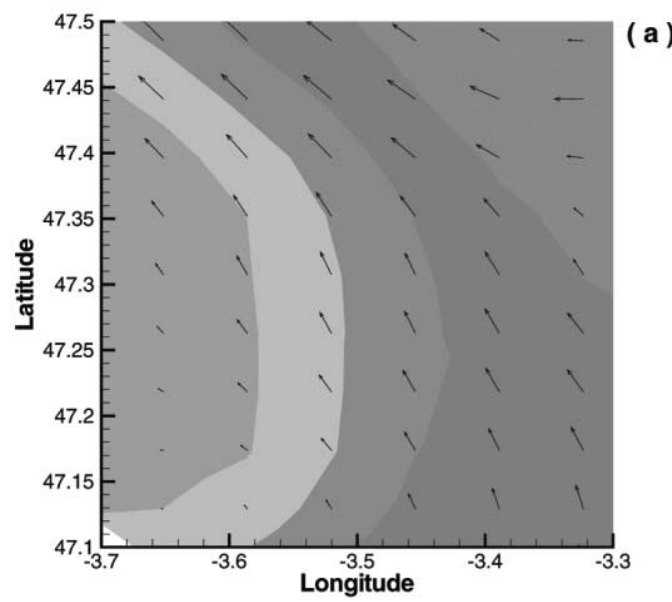

For the numerical treatment, a method of finite volumes was developed. Details about the mesh-size and the type can be found in (Arino et al., 1999).

\subsection{Physical parameters}

Physical parameters include temperature, pressure, salinity, vertical mixing coefficient and current velocity (figure 2). Of this list, the model explicitly uses temperature, vertical mixing coefficient and current velocity, all of them provided by the circulation model due to Lazure and Jegou (1998): briefly stated, this model generates values of the physical parameters, based on real data. The data used here are from the year 1996, end of March through May, for NE Bay of Biscay. Temperature is roughly uniform throughout the water column and varies within the range $10.5-12^{\circ} \mathrm{C}$, horizontally. The current speed varies approximately in the same range as $u_{2}$ in section two. Vertical speed is negligible compared to the horizontal one. The variation in direction of the horizontal velocity is well marked in the western part of the area, the deepest one, pointing to the south-west in the upper part of the water column and pointing to the south-east in the lower part. Over all, the situation is quite diverse, with, in some places, variation in the south-north direction only, and in some other places no change in direction.

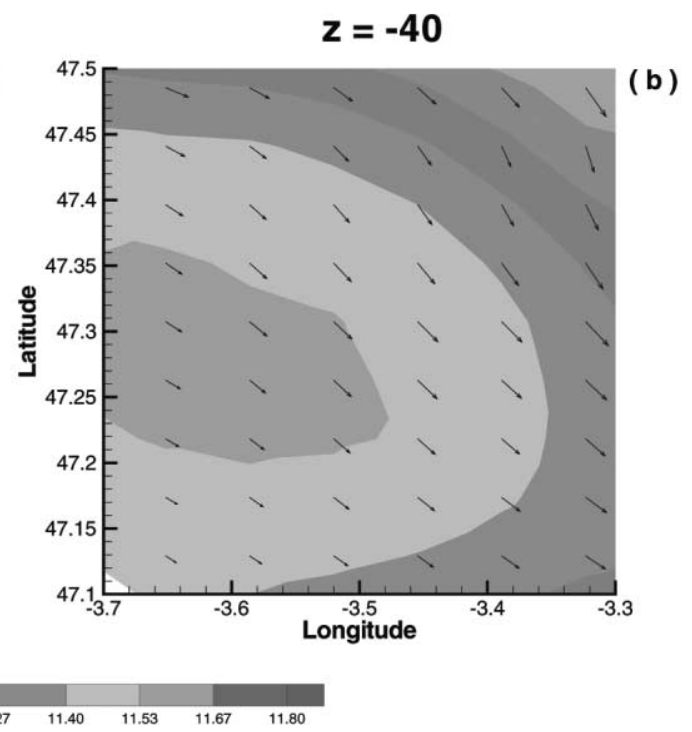

Figure 1. Zoomed horizontal cross-sections of the currents west of the spawning grounds at two different depths (10 $\mathrm{m}$ and $40 \mathrm{~m})$. 


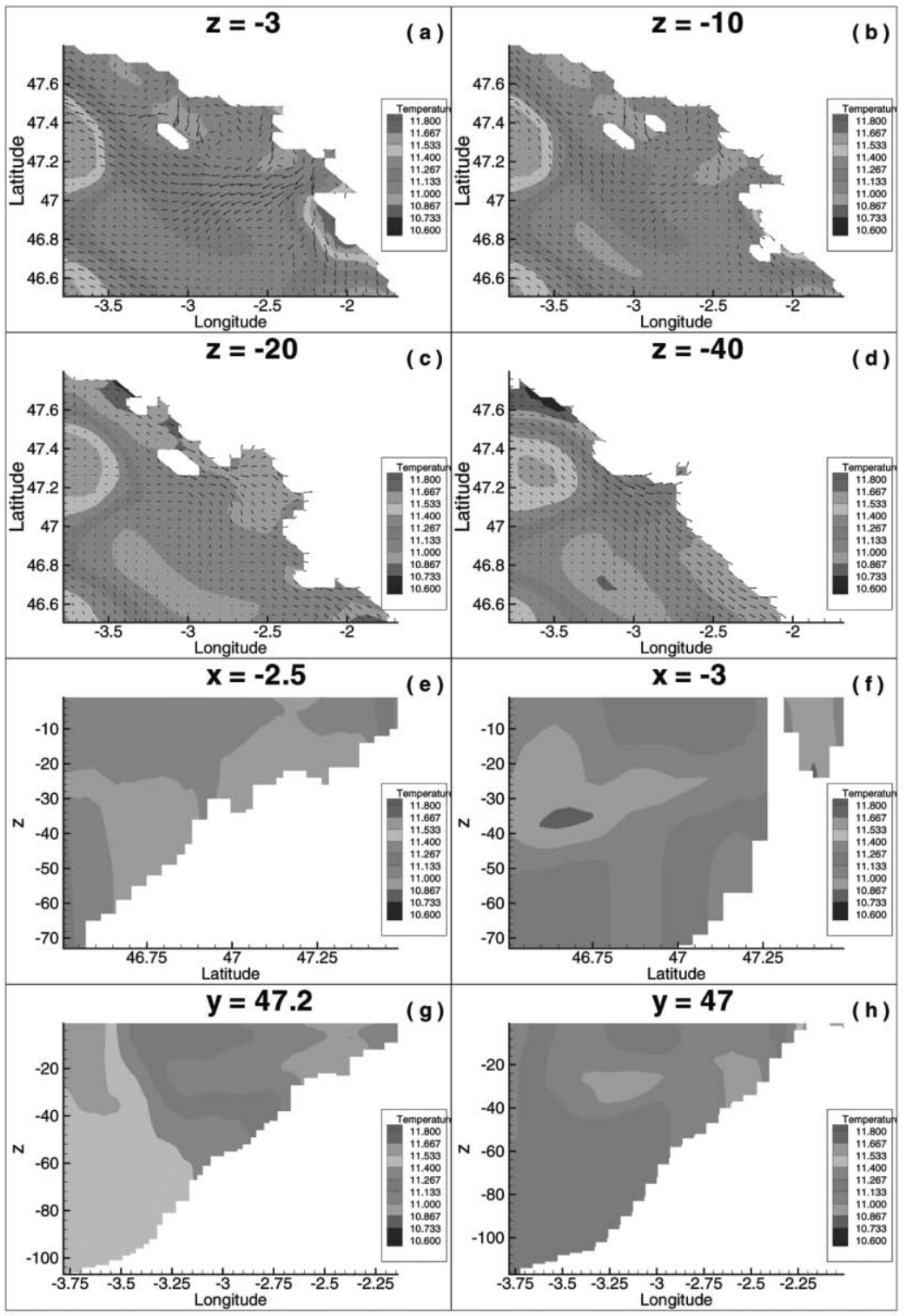

Figure 2. Horizontal cross-sections of temperature and the currents at respective depths of $3 \mathrm{~m}$ (a), $10 \mathrm{~m} \mathrm{(b),} 20 \mathrm{~m} \mathrm{(c),} \mathrm{and} 40 \mathrm{~m} \mathrm{(d)}$; vertical latitudinal cross-sections at $2.5^{\circ} \mathrm{W}$ (e) and $3^{\circ} \mathrm{W}$ (f); vertical longitudinal cross-sections at $47^{\circ} \mathrm{N}$ (g) and $47.2^{\circ} \mathrm{N}(\mathbf{h})$.

\subsection{Vertical cross-sections}

Figure 3 represents cross-sections of the sea by a vertical plane. It is important to notice that in all the simulations presented in this section the initial number and distribution of eggs are selected arbitrarily. In fact, the following distribution was used: $25 \mathrm{eggs} \mathrm{m}^{-3}$ at $39 \mathrm{~m}$ deep, 50 eggs $\mathrm{m}^{-3}$ at $40 \mathrm{~m}$ deep, 25 eggs $\mathrm{m}^{-3}$ at $41 \mathrm{~m}$ deep, and 0 elsewhere. In figure $3 a$, the material shown is a cross section of eggs aged one day: we observe a small heterogeneity. Figure $3 b$ is a cross-section of the larvae aged 12 days: heterogeneity has increased and vertical hauls will give quite different results according to where they are performed.

\subsection{Horizontal cross-sections}

Starting from an initial distribution of eggs uniform throughout the whole spawning ground, we represent 
(a)
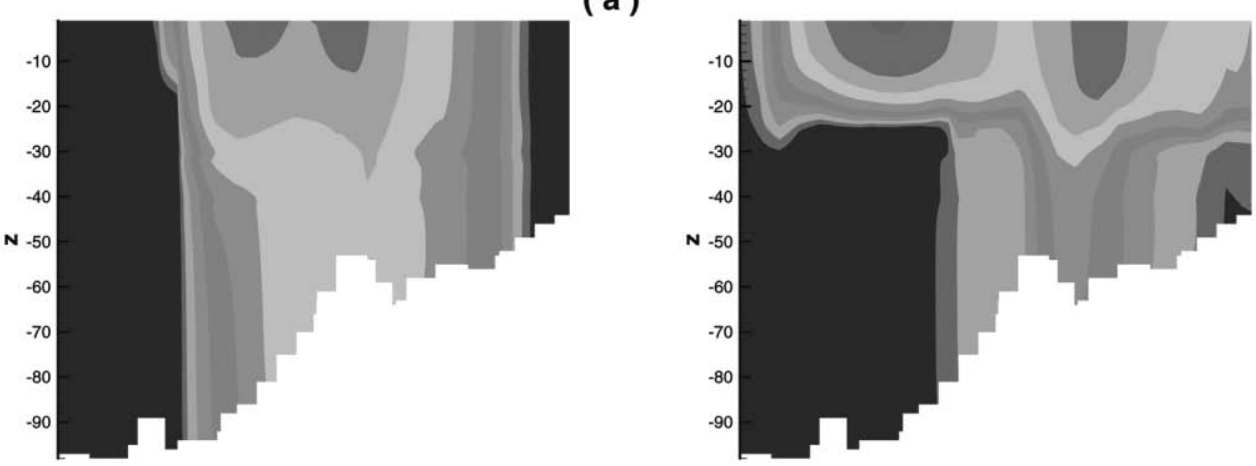

(b)

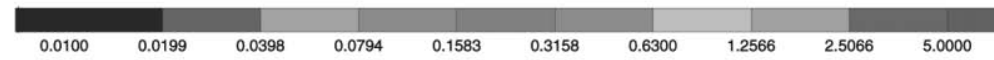

Figure 3. Vertical cross-section of eggs aged one day (a), and larvae aged 12 days (b). Units: number of eggs $\mathrm{m}^{-3}$.
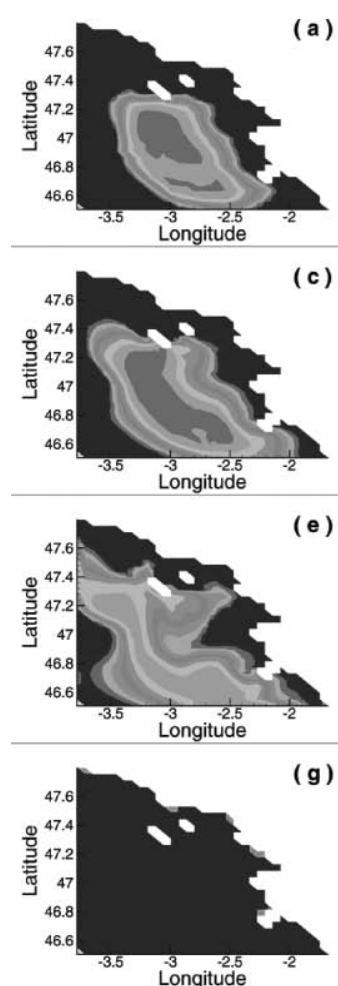

(g)

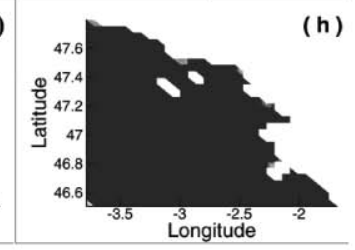

$\begin{array}{llllllllll}0.0100 & 0.0199 & 0.0398 & 0.0794 & 0.1583 & 0.3158 & 0.6300 & 1.2566 & 2.5066 & 5.0000\end{array}$

(b )

(f)

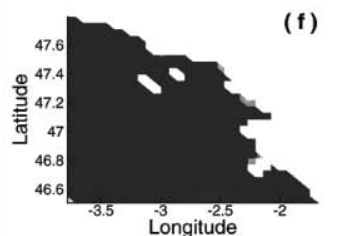

(h)

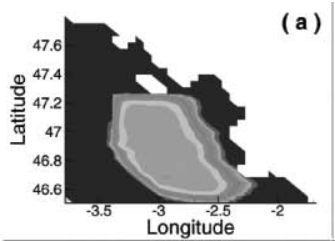

(c)
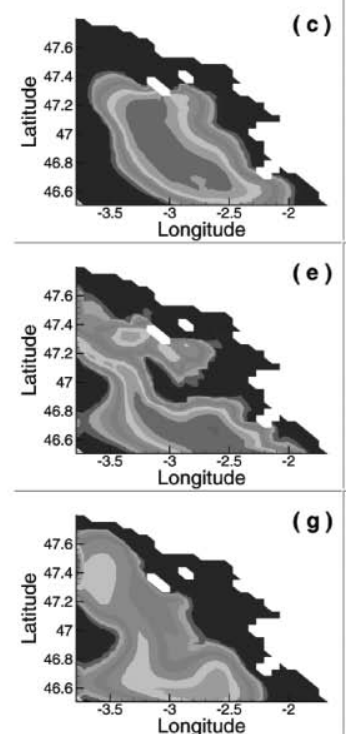

(g)

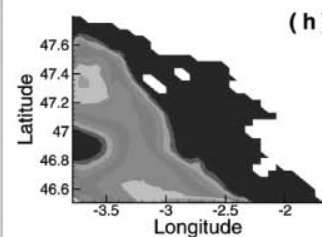

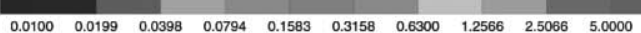

Figure 4. Starting from an initial patch of eggs aged zero day, horizontal cross-section of the larval population, computed at 8 different days (1, 2 , $4,6,12,22,32,51)$, same hour (14h00, daylight), same depth $(10 \mathrm{~m})$ (left panel, a-h). Corresponding picture at night $(02 \mathrm{~h} 00)$ instead of the day (right panel, a-h). Units: number of eggs $\mathrm{m}^{-3}$. 
horizontal cross-sections (at $z=-10 \mathrm{~m}$ ) made on days 1 , 2, 4, 6, 12, 22, 32 and 52, at two different hours: $14 \mathrm{~h} 00$ (daytime) and $02 \mathrm{~h} 00$ (night). The results are to be compared to those described in Koutsikopoulos et al. (1991, figure 10). Note that the values obtained represent integrals of densities over a $1 \mathrm{~m}$ deep layer.

The interpretation of figure 4 is not obvious. The upper layers tend to get empty during the day while the lower layers tend to empty during the night. Communication between the various layers never stops, which explains that layers that are empty at some time may replenish later. The main effect in the range of 50 days and over seems to be a drift along the coast, rather than towards the coast. A better view of the displacement towards the coast is provided by figure 5 where the population has been integrated throughout the whole water column.

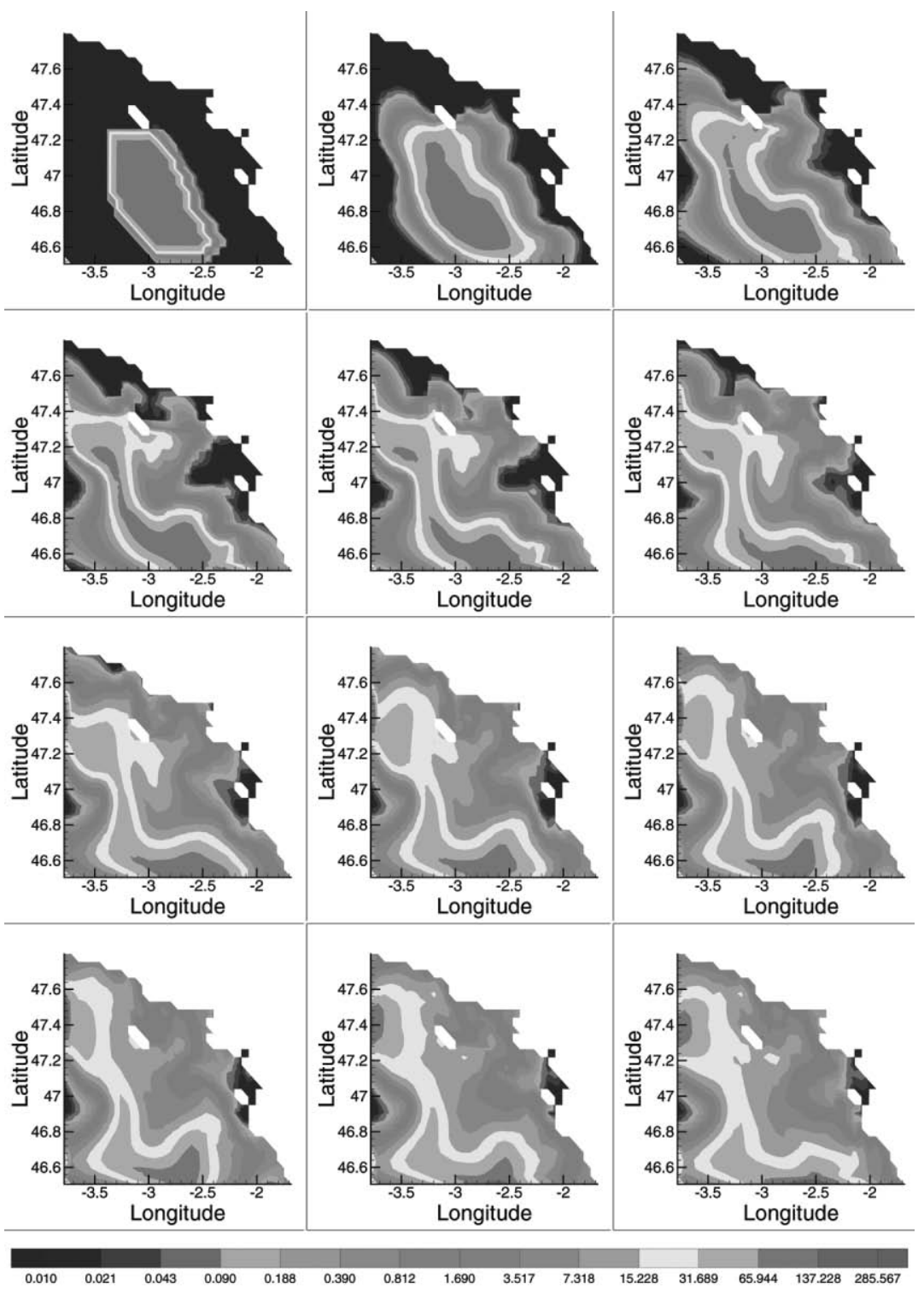

Figure 5. Totalization of the larva density throughout the water column every four days of a period over a month. 


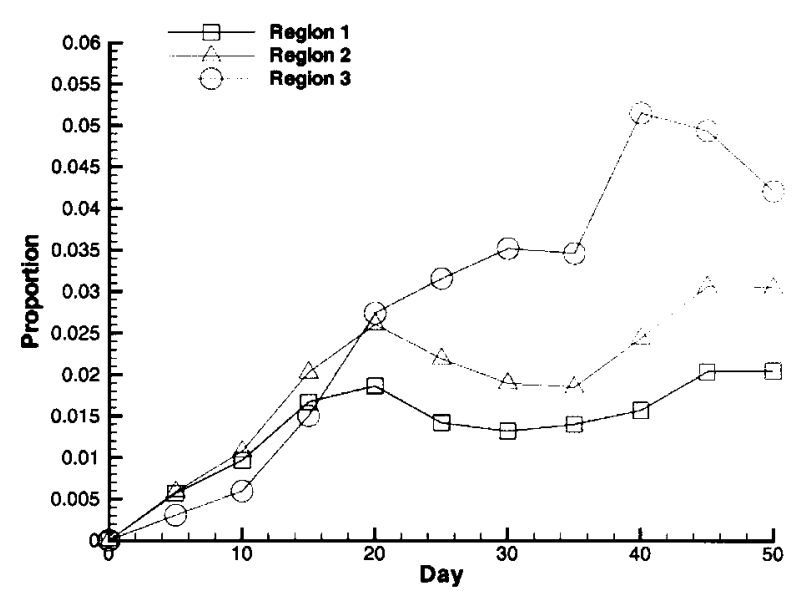

Figure 6. The three graphs represent the arrival rate of the larvae as a function of age in the vicinity of the coast. Each of the three graphs is associated to a particular region: region 1, a diamond-shaped region with vertices at $(2.4697 \mathrm{~W}, 46.9956 \mathrm{~N}),(2.338 \mathrm{~W}, 46.9956 \mathrm{~N}),(2.929 \mathrm{~W}$, $47.3519 \mathrm{~N}),(2.798 \mathrm{~W}, 47.3519 \mathrm{~N})$ (squares); region 2, also a diamondshaped region, a slightly bigger domain with vertices at $(2.4697 \mathrm{~W}$, $46.9956 \mathrm{~N}),(2.2727 \mathrm{~W}, 46.9956 \mathrm{~N}),(2.9949 \mathrm{~W}, 47.3519 \mathrm{~N}),(2.7323 \mathrm{~W}$, $47.3519 \mathrm{~N}$ ) (triangles); region 3, a region enclosed between the $46.9 \mathrm{thN}$ and 47.8thN parallels in the south-north direction, the coast, and a straight line defined by the equation in the east-west axis, $y=-0.73 x+45.20$ (circles).

\subsection{Proportions of larvae arriving within a close distance to the coast}

Our objective in performing the simulations presented in this subsection was to compare estimates of the recruitment rate given by a 3D model incorporating real physical data (currents) to those provided by the $2 \mathrm{D}$ model of section two. Following the same idea as in section two, we consider a region $\Omega$ in the spawning ground and a region $D$ located closer to the nurseries than $\Omega$. To the same region $\Omega$ we associate three different regions $D_{1}, D_{2}$ and $D_{3}$, such that $D_{1} \subset D_{2} \subset D_{3}$. For each of them, we evaluate the proportion of the eggs produced in $\Omega$ which survive as larvae at least until they reach the given region. In section two, the computation was made with the larvae that reach the admissible region at a certain threshold size. Since growth in size was not incorporated in the present simulation, the count must be done in a different way. What we do here is just count the proportion of those arrived in $D_{i}$ since day zero. The results are shown in figure 6.

\section{DISCUSSION}

First of all, the results of the three domains are mutually comparable. In general, the proportion is bigger for the larger domain, though we see that the graphs for $D_{1}$ and $D_{3}$ and for $D_{2}$ and $D_{3}$ respectively, cross at some point. This is certainly a weird fact, which is due to the approximation process, that is, the grid that approximates $D_{1}$ is not strictly a subfamily of the one approximating $D_{2}$.

Secondly, each graph is made up of two or more parts on each of which the slope has a fixed sign, positive or negative: since no mortality is accounted for, the only admissible interpretation is that larvae can move in and out of each $D_{i}$.

Finally, the numbers compare with the highest values of $\widehat{E(i)}$ obtained in section two, table II, which, we recall, are estimates of the proportion of larvae initiating metamorphosis. The comparison to be made with the highest point in the graph of $D_{i}: D_{1}$ would be with the region reached by the more mature larvae, the peak reached on this graph at age $a=50$ days would roughly correspond to the proportion of larvae having reached metamorphosis. Discrepancies between the two counts may be caused by several factors: on the one hand, the computation of $\widetilde{E(i)}$ was done on the ground that metamorphosis occurs at 55 days of age (except for the simulation $E(10)$ where the age of transition was taken to be 40 days), while the $D_{\mathrm{i}}$ 's are computed over the first fifty days; on the other hand, as already noticed, none of the regions $D_{i}$ is invariant: oscillations of the counts suggest that there are migrations in and out each of these regions. In principle, the 'theoretical' estimate, computed by means of formula (8) is minimal, and indeed the values of $\widehat{E(i)}$ for all $i \neq 2$ are small compared to those exhibited by figure 6 . E(2) corresponds to the lowest speed of the current (of all the simulations), therefore, to the case when horizontal diffusion plays comparatively a bigger role. It is interesting to observe that this situation leads to results of the same order as when using the data of the numerical circulation model, which does not account for horizontal diffusion explicitly.

\section{REFERENCES}

Amara, R., Lagardère, F., 1995. Taille et âge au début de la métamorphose chez la sole, Solea solea (L.), du golfe de Gascogne. ICES J. Mar. Sci. 52, 247-256. 
Arino, O., Koutsikopoulos, C., Ramzi, A., 1996. Elements of mathematical modeling of evolution in number of a sole population. $\mathrm{J}$. Biol. Syst. 4, 4, 445-458.

Arino, O., Boussouar, A., Prouzet, P., 1999. Modeling of the larval stage of the anchovy of the Bay of Biscay. Estimation of the rate of recruitment in the juvenile stage, Final report, Project 96/048 DG XIV EC.

Arino, O., Prouzet, P., 1998. Modeling of the larval stage of the anchovy of the Bay of Biscay. Estimation of the rate of recruitment in the juvenile stage, Interim progress report, Project 96/048 DG XIV EC.

Horwood, J., 1993. The Bristol Channel sole (Solea solea (L.)): a fisheries case study. Adv. Mar. Biol. 29, 215-367.
Koutsikopoulos, C., Fortier, L., Gagne, J.A., 1991. Cross-shelf dispersion of Dover sole (Solea solea (L.)) eggs and larvae in Biscay Bay and recruitment to inshore nurseries. J. Plankton Res. 13, 923-945.

Lazure, P., Jegou, A.M., 1998. 3D modelling of seasonal evolution of Loire and Gironde plumes on Biscay Bay continental shelf. Oceanol. Acta 21, 165-177.

Pond, S., Pickard, G., 1983. Introductory dynamical oceanography. Pergamon Press, Oxford.

Ramzi, A., Arino, O., Koutsikopoulos, C., Boussouar, A., Lazure, P., 2001. Modelling and numerical simulations of larval migration of the sole (Solea solea (L.)) of the Bay of Biscay. Part 1: modelling. Oceanol. Acta 24, 00. 